\title{
ÉTICA E CINEMA: UMA PROPOSTA INTERDISCIPLINAR PARA A EDUCAÇÃO AMBIENTAL
}

\author{
Tânia Mara De Bastiani ${ }^{1}$, Marcelo Barcellos da Rosa ${ }^{2}$ \\ 1 Especialista em Educação Ambiental - UFSM, taniamaradb@hotmail.com \\ 2 DQ-CCNE/UFSM, marcelobdarosa@gmail.com
}

\section{RESUMO}

O Ensino de Filosofia e a Educação Ambiental são obrigatórios dentro do currículo escolar. Partindo desta realidade, este trabalho teve por objetivo Integrar a temática Educação Ambiental em aulas de Ética, conteúdo programático da disciplina Filosofia, utilizando como recurso pedagógico o Cinema. Para atingir o objetivo elaborou-se uma "proposta" de interdisciplinaridade entre Ética e Cinema para demonstrar que temáticas ambientais podem ser discutidas dentro de uma aula de Filosofia. A "proposta" compreende três momentos: 1) sensibilização antes da exibição do filme através das questões "O ser humano é dono da natureza ou parte dela?" e, "A lei é suficiente para conscientizar as pessoas sobre a importância do meio ambiente?"; 2) Exibição do filme Wall-E; 3) Discussão dos conceitos de Antropocentrismo, Holismo, Sociedade de Consumo, Moral e Lei. Ela foi pensada para alunos do Ensino Médio, na série em que o conteúdo de Ética estiver incluída. Por caracterizar-se como "proposta" este trabalho é apenas a exposição de como trabalhar interdisciplinarmente Ética e Cinema tendo como finalidade a Educação Ambiental.

Palavras-chave: Educação Ambiental; Ensino de Filosofia; Cinema

\section{ABSTRACT}

The Teaching of Philosophy and Environmental Education are required in the school curriculum. From this fact, this monograph integrates the theme of environmental education in ethics classes, content that is part of the content of philosophy, using the film as a pedagogical resource. To fulfill the objective, we performed a literature review concerning the obligation of the Teaching of Philosophy and Environmental Education in the school curriculum and about the importance of film used as a teaching resource in general and specifically to the discipline of philosophy.And yet, we make a "proposal" of interdisciplinarity in Ethics and Cinema to show that environmental issues can be discussed in a philosophy class and contributing to environmental education. The "proposal" is composed of three moments: 1) Sensitize before the movie through the questions "Man is the master of nature or man is part of nature?" and, "The law is enough to make people aware of the importance of the environment?"; 2) Show the movie Wall-E; 3) Talk about concepts Anthropocentrism, Holism, Consumer Society, Morality and the Law. It is designed for high school students whose curriculum has content Ethics. Being a "proposal" This work is just one of the ways of working as an interdisciplinary Ethics and Cinema intended for the Environmental Education.

Keywords: Environmental Education; Teaching Philosophy; Cinema. 


\section{INTRODUÇÃO}

O Ensino de Filosofia e a Educação Ambiental são obrigatórios no currículo escolar. O primeiro para instituições que adotarem organização escolar por disciplinas e a outra, como uma prática educativa de todos os níveis e modalidades do ensino formal, devendo ser integrada, contínua e permanente, sem, no entanto, ser uma disciplina específica.

Legalmente, a Educação Ambiental é uma temática que deve perpassar todas as disciplinas escolares, fazendo parte do Ensino Formal. Talvez os professores das ciências naturais estejam mais acostumados a abordar a temática, mas como os professores das ciências humanas podem integrá-la as suas disciplinas? Ou, mais especificamente, como integrar Ensino de Filosofia e Educação Ambiental?

Apesar da Educação Ambiental ser obrigatória para todos os níveis de ensino, nem sempre este conteúdo vem sendo trabalhado adequadamente dentro de sala de aula, pois, muitas vezes, segundo Gonçalves e Cruz-Silva (2009, p. 31) "encontra-se resistência por parte dos professores que optam pelo ensino tradicionalista, que acabam não inserindo este conteúdo nas disciplinas, ficando somente por responsabilidade dos professores da disciplina de Ciências Naturais trabalharem este tema".

Este trabalho propôs romper estas resistências e buscou demonstrar que, disciplinas das ciências humanas, em geral, e o Ensino de Filosofia, em específico, podem trabalhar assuntos relacionados ao meio ambiente, mesmo que estes não estejam explícitos em seus conteúdos programáticos.

"Ética" é um dos conteúdos programáticos da disciplina de Filosofia. Este trabalho descreve através de uma "proposta" pedagógica que compreende três momentos - 1) sensibilização antes da exibição do filme através das questões "O ser humano é dono da natureza ou parte dela?" e, "A lei é suficiente para conscientizar as pessoas sobre a importância do meio ambiente?"; 2) Exibição do filme Wall-E; 3) Discussão dos conceitos de Antropocentrismo, Holismo, Sociedade de Consumo, Moral e Lei - que é possível integrar interdisciplinarmente Ética e Cinema e contribuir para a Educação Ambiental de alunos do Ensino Médio dentro de uma aula de Filosofia.

\section{METODOLOGIA}

Levando em consideração a obrigatoriedade da disciplina Filosofia no Ensino Médio (lei 11.684/08) e da Educação Ambiental como uma prática educativa de todos os níveis e modalidades do ensino formal, devendo ser integrada, contínua e permanente, sem, no entanto, ser uma disciplina específica (lei 9.795/99), este trabalho é uma "proposta" de integração da temática de Educação Ambiental ao Ensino de Filosofia, através do conteúdo programático de "Ética", utilizando como recurso pedagógico o cinema, numa perspectiva interdisciplinar.

Por caracterizar-se como "proposta", ele não tem os resultados da sua aplicação, mas está focado na descrição de uma atividade que envolve o filme Wall-E para trabalhar questões referentes à Ética Ambiental. Este conceito é definido por Barbosa $(2008$, p. 07) como sendo "uma reflexão sobre os comportamentos humanos relativos ao ambiente. Estes comportamentos surgem a partir da percepção da necessidade de melhorar a relação homemnatureza, que caminhe no sentido de uma dependência menos predatória e mais respeitosa". 


\section{Filme Wall-E e Educação ambiental - (Propostas pedagógicas)}

TRABALHO 1

\begin{tabular}{|l|l|}
\hline Título & $\begin{array}{l}\text { "WALL-E": O uso de um filme de animação na educação ambiental com temas transversais } \\
\text { dos PCN }\end{array}$ \\
\hline Autores & Fabiana Rodrigues Santos (UTFPR) e Luís Paulo de Carvalho Piassi (UTFPR) \\
\hline Publicação & $\begin{array}{l}\text { Artigo publicado nos anais do II Simpósio Nacional de Ensino de Ciência e Tecnologia } \\
\text { (Curitiba, 2010). }\end{array}$ \\
\hline Resumo & $\begin{array}{l}\text { Articular em sala de aula a disciplina com os Temas Transversais dos PCN's tem sido uma } \\
\text { tarefa árdua para muitos professores. Fazer essa articulação e relacionar com a realidade } \\
\text { vivida pela sociedade nos dias de hoje também é complicado. Pensando nisso, este trabalho } \\
\text { tem por objetivo fazer um levantamento dos Temas Transversais que podem ser } \\
\text { trabalhados com o uso do filme Wall-E, bem como avaliar se este pode ser utilizado como } \\
\text { uma forma de prática pedagógica referente à temática ambiental, trazendo uma proposta } \\
\text { de interdisciplinaridade e inovações. Procurou-se verificar se os alunos percebem por meio } \\
\text { dessa atividade, a importância de se conservar o meio ambiente. Para a tomada de dados, o } \\
\text { filme foi exibido em uma classe de 5o série do Ensino Fundamental II, em que foi realizada } \\
\text { discussão e atividades com os alunos, assim como a gravação de áudio e vídeo do processo. }\end{array}$ \\
\hline Palavras-chave & $\begin{array}{l}\text { Filme de Fiç̧ão Científica, Recurso Didático, Temáticas Ambientais, Ensino de Educação } \\
\text { Ambiental. }\end{array}$ \\
\hline Acesso & http://www.pg.utfpr.edu.br/sinect/anais2010/artigos/Ens Bio/art184.pdf \\
\hline
\end{tabular}

\section{TRABALHO 2}

\begin{tabular}{|l|l|}
\hline Título & Wall-e na sociedade do descarte - uma reflexão sobre o consumo como organizador da vida \\
\hline Autores & $\begin{array}{l}\text { Carla Simone Corrêa Marcon (UNIVERSIDADE LUTERANA DO BRASIL) e Sandro Faccin } \\
\text { Bortolazzo (ULBRA) }\end{array}$ \\
\hline Publicação & Artigo da internet / ano não informado \\
\hline Resumo & $\begin{array}{l}\text { Um robô responsável por compactar lixo deixado pelos seres humanos é o núcleo do longa- } \\
\text { metragem WALL-E, animação da Pixar. Este artigo procura articular perspectivas a partir de } \\
\text { algumas preocupações permanentes frente a uma era movida pela instantaneidade e } \\
\text { caracterizada pelo desperdício, consumo excessivo e o constante descarte. O filme revela um } \\
\text { panorama do planeta no ano de 2700, expondo questionamentos de cunho ambiental, } \\
\text { político, tecnológico e sociológico. Ferramentas teórico-conceituais tomadas de Zygmunt } \\
\text { Bauman são empregadas neste trabalho para assinalar características da contemporaneidade } \\
\text { diante dos problemas enfrentados pela sociedade do efêmero, da velocidade e do } \\
\text { espetáculo. Para tal análise, utiliza-se o conceito de pedagogia cultural a partir de Shriley } \\
\text { Steinberg e Joe Kincheloe com ênfase no seu caráter pedagógico. A utilização de um texto } \\
\text { fílmico imerso no campo dos estudos culturais tem o intuito de apontar o cinema como um } \\
\text { meio para o "ensinar". Tendo como ênfase as questões relacionadas ao consumo e a } \\
\text { educação, bem como suas repercussões na vida contemporânea, a película como um } \\
\text { instrumento pedagógico tem se mostrado um importante artefato para pensar a formação de } \\
\text { sujeitos na contemporaneidade. WALL-E, além de ter sido indicado ao Oscar e levado a } \\
\text { estatueta, traz ao público um alerta com relação ao meio ambiente, o uso das novas } \\
\text { tecnologias e suas consequências sociais. }\end{array}$ \\
\hline Palavras-chave & $\begin{array}{l}\text { Educação, Pedagogias Culturais, Sociedade de Consumidores. } \\
\text { http://alb.com.br/arquivo- } \\
\text { morto/edicoes_anteriores/anais17/txtcompletos/sem16/COLE_2665.pdf }\end{array}$ \\
\hline
\end{tabular}


TRABALHO 3

\begin{tabular}{|c|c|}
\hline Título & Discutindo a educação ambiental em sala de aula sob o viés do filme wall-e \\
\hline Autores & $\begin{array}{l}\text { Simoni Priesnitz Friedrich (Colégio La Salle Medianeira); Eliane Gonçalves do Santos (Escola } \\
\text { Municipal D. Pedro II); Marlete Gut (Colégio La Salle Medianeira) }\end{array}$ \\
\hline Publicação & $\begin{array}{l}\text { Trabalho apresentado no II Congresso Internacional de Educação Cientifica e Tecnológica } \\
\text { (Santo Ângelo, 2012) }\end{array}$ \\
\hline Resumo & $\begin{array}{l}\text { O advento de novas tecnologias de comunicação, nas escolas, acelera o interesse do } \\
\text { educando pelo uso e pelo estudo através do tecnológico. Isso nos induz a pensar sobre as } \\
\text { formas de como esses instrumentos contribuem para a melhoria } \\
\text { do ensino. O cinema é uma tecnologia educacional e pode ser considerado um } \\
\text { instrumento de aprendizagem e de possibilidades de construção de conhecimento. O seu } \\
\text { uso em sala de aula representa uma oportunidade de trazer ao espectador esclarecimentos e } \\
\text { reflexão sobre tema, ilustração e demais elementos da narrativa.Os filmes são excelentes } \\
\text { formas a serem utilizadas em todas as áreas de formação e, também, podem ser utilizados } \\
\text { em estudos, em análises e em práticas nas aulas de todos os componentes curriculares, } \\
\text { inclusive na Educação Ambiental, uma vez que esta surge como uma necessidade das } \\
\text { sociedades atuais, à medida que as situações socioambientais têm sido discutidas na } \\
\text { sociedade e na política, devido à degradação do meio. Dessa forma, a discussão da Educação } \\
\text { Ambiental, na escola, oportuniza ao educando uma reflexão crítica da realidade da qual ele } \\
\text { faz parte. Diferentes materiais didáticos voltados para a Educação Ambiental têm sido } \\
\text { produzidos de forma crescente. Neste artigo, propomos a discussão e análise do estudo e } \\
\text { dos princípios da Educação Ambiental, no filme Wall-E (Wall-E, Estados Unidos, 2008). Diante } \\
\text { desse contexto, é apresentada a possibilidade da utilização do cinema como tecnologia } \\
\text { educacional, ilustrativa e de aprofundamento dos conteúdos sobre meio ambiente em } \\
\text { escolas de educação básica. A análise permite evidenciar o filme Wall-E como categoria } \\
\text { epistemológico-problematizadora. E o cinema como uma tecnologia formadora e não apenas } \\
\text { como um recurso tecnológico complementar e ilustrativo. Trazemos, neste artigo, a proposta } \\
\text { da utilização de recortes de filmes comerciais em sala de aula, para análise e estudo da } \\
\text { Educação Ambiental, buscando (re)escrever uma nova abordagem do processo investigativo } \\
\text { e reflexivo de aprendizagem na educação. A ferramenta computacional Movie Maker é uma } \\
\text { possibilidade didática de auxílio aos professores na utilização, integral ou de recortes, de } \\
\text { filmes comercias em sala de aula. }\end{array}$ \\
\hline Palavras-chave & Educação ambiental, tecnologia, filmes e possibilidades pedagógicas. \\
\hline Acesso & $\begin{array}{l}\text { http://www.santoangelo.uri.br/ciecitec/anaisciecitec/2012/resumos/ } \\
\text { POSTER/poster59.pdf }\end{array}$ \\
\hline
\end{tabular}

TRABALHO 4

\begin{tabular}{|l|l|}
\hline Título & Ficção ou realidade: uma perspectiva do futuro do nosso planeta na visão infantil \\
\hline Autores & Ana Paula Ott; Manuela Candéo \\
\hline Publicação & $\begin{array}{l}\text { Trabalho apresentado no II Simpósio Nacional de Ensino de Ciência e Tecnologia (Curitiba, } \\
\text { 2010) }\end{array}$ \\
\hline Resumo & $\begin{array}{l}\text { O presente artigo faz uma análise do pensamento de quinze crianças entre } 8 \text { e } 9 \text { anos sobre a } \\
\text { perspectiva de futuro em relação ao meio ambiente, utilizando como ferramenta o filme da } \\
\text { Disney Wall-E. A ficção foi utilizada para identificar se a consciência ambiental e social pode } \\
\text { ser estimulada a partir de uma obra infantil trazendo reflexões sobre o futuro do planeta, } \\
\text { como também realizar um levantamento das perspectivas e levantar reflexões sobre o que } \\
\text { poderá acontecer se não preservarmos o meio ambiente. Após assistirem ao filme as } \\
\text { crianças realizaram uma redação com duas perguntas chave: “O que eu posso fazer para que } \\
\text { o nosso planeta não se torne como o planeta Terra do filme?" e "O que eu quero para o } \\
\text { futuro da sociedade?". Os textos foram analisados e observou-se uma preocupação não só } \\
\text { com o futuro ambiental como também o social. }\end{array}$ \\
\hline Palavras-chave & crianças; filme; meio ambiente. \\
\hline Acesso & http://www.pg.utfpr.edu.br/sinect/anais2010/artigos/EnsCienSI/art149.pdf \\
\hline
\end{tabular}




\section{TRABALHO 5}

\begin{tabular}{|l|l|}
\hline Título & UM PEDIDO DE SOCORRO DO PLANETA TERRA: Cinema de animação e Educação Ambiental \\
\hline Autores & $\begin{array}{l}\text { Marisa de Mello Luvielmo (FURG); Regina Zauk Leivas } \\
\text { (Universidade Católica de Pelotas) }\end{array}$ \\
\hline Publicação & Rev. eletrônica Mestr. Educ. Ambient. ISSN 1517-1256, v. 22, janeiro a julho de 2009 \\
\hline Resumo & $\begin{array}{l}\text { Esse trabalho tem por finalidade colaborar para as profícuas discussões que a educação } \\
\text { ambiental vem fomentando apontando para importância que o cinema/filme de animação } \\
\text { pode ter quando utilizado neste âmbito. Tendo como objetivo perceber o cinema como uma } \\
\text { fonte produtiva de conhecimento, podendo a educação ambiental valer-se dele para discutir, } \\
\text { debater, refletir, propagar suas vertentes. No trabalho é utilizada como objeto de análise a } \\
\text { animação Wall.e, dos Estúdios da Walt Disney Pictures/Pixar Animation Studios, que aborda } \\
\text { questões ambientais através de sua narrativa fílmica. A animação Wall.e pode levar ao } \\
\text { espectador - seja ele criança, jovem ou adulto - a uma posição de autorreflexão sobre atitudes } \\
\text { que vêm sendo tomadas em relação ao nosso Planeta. Apropriando-me de conceitos que } \\
\text { Edgar Morin discute nas suas obras Educar na era planetária e A cabeça bem-feita, proponho- } \\
\text { me, nesse estudo, um diálogo entre a narrativa fílmica e os temas ambientais, um despertar de } \\
\text { uma sociedade-mundo para o entendimento de que todos nós somos filhos de um mesmo e } \\
\text { único cosmo, considerando que a educação e a "educação ambiental" possuem um papel } \\
\text { crucial para a compreensão do conhecimento referente à nossa sustentação planetária. O } \\
\text { cinema pode, assim, se tornar uma fonte de conhecimento dentro da educação ambiental } \\
\text { através do que busquei demonstrar com o estudo da animação Wall.e. }\end{array}$ \\
\hline Palavras-chave & \begin{tabular}{l} 
cinema/animação, educação e educação ambiental. \\
\hline htesp://www.remea.furg.br/edicoes/vol22/art33v22.pdf
\end{tabular} \\
\hline
\end{tabular}

\section{TRABALHO 6}

\begin{tabular}{|c|c|}
\hline Título & Educação Ambiental, cinema e biopoder: uma discussão possível \\
\hline Autora & Marisa de Mello Luvielmo (FURG) \\
\hline Publicação & $\begin{array}{l}\text { Dissertação (Mestrado em Educação Ambiental) - Universidade Federal do Rio Grande, Rio } \\
\text { Grande, } 2011 .\end{array}$ \\
\hline Resumo & $\begin{array}{l}\text { A presente dissertação parte da possibilidade de uma discussão entre os campos de saberes } \\
\text { atrelados à educação ambiental e ao cinema. A partir dessa possibilidade o objetivo é analisar } \\
\text { discursos produzidos através do corpus discursivo - o filme de animação Wall.E que se refere a } \\
\text { crise ambiental que vive-se na contemporaneidade. Na pesquisa toma-se como principal } \\
\text { referencial teórico os estudos do filósofo francês Michel Foucault, principalmente no que ele } \\
\text { intitula por Biopoder. A pesquisa procura evidenciar o cinema como mídia que interpela os } \\
\text { sujeitos através de seus discursos. A educação ambiental é percebida nesta investigação a } \\
\text { partir de dois olhares: o primeiro que a percebe com um dispositivo de seguridade que tem } \\
\text { por finalidade regular e conduzir a conduta dos sujeitos; e um segundo que faz referência aos } \\
\text { estudos das três ecologias de Felix Guattari. Na dissertação, a educação ambiental passa a ser } \\
\text { considerada como prática que caracteriza o que Guattari denomina como "ecosofia". Uma } \\
\text { ecosofia, como prática ético-política e estética, que condiz com a maneira de viver no planeta } \\
\text { sob as mudanças desse tempo contemporâneo. Para tanto, como forma de entender a } \\
\text { contemporaneidade busca-se respaldo teórico em algumas problematizações referenciadas } \\
\text { pelo sociólogo polonês Zygmunt Bauman. Trata-se de conceitos muito evidentes na animação, } \\
\text { principalmente condizentes ao lixo, consumo e descartabilidade. O estudo discute a crise } \\
\text { ambiental vivida por cada um de nós, entendo o cinema como potente ferramenta para } \\
\text { pensar o mundo atual. }\end{array}$ \\
\hline Palavras-chave & Educação Ambiental, Cinema e biopoder \\
\hline Acesso & http://repositorio.furg.br:8080/jspui/handle/1/2232 \\
\hline
\end{tabular}




\section{Como trabalhar o Filme Wall-E em aulas de Filosofia?}

1. Antes da Exibição do Filme: Sensibilizar com as seguintes questões: "O ser humano é dono da natureza ou parte dela?" e, "A lei é suficiente para conscientizar as pessoas sobre a importância do meio ambiente?"

\section{Assistir o Filme}

3. Depois da Exibição do Filme: Fazer uma discussão sobre os conceitos de Antropocentrismo, Holismo, Sociedade de Consumo, Moral e Lei.

\section{Onde pode ser aplicada a proposta? Para quem?}

Partindo do fato de que a disciplina Filosofia é obrigatória em todas as séries do Ensino Médio, esta proposta pode ser aplicada na série em que o conteúdo de Ética estiver presente, já que, normalmente, dependendo da Instituição de Ensino, ele pode estar presente no 10 ano onde os alunos tem em média 13 a 14 anos, ou no 2 ano onde os alunos têm entre 14 e 15 anos, ou ainda no 3으. ano, onde possuem de 15 a 16 anos.

\section{RESULTADOS E DISCUSSÃO}

Para se trabalhar o Filme Wall-E dentro das aulas de Filosofia com alunos do Ensino Médio deve-se:

1. Antes da exibição do filme: Antes de iniciar a exibição, é importante, segundo Nazário (2005, p. 544) "situar a temática para que possam surgir comentários, funcionando como um aquecimento para o grupo". Uma maneira de situar a temática da Educação Ambiental antes da exibição do filme Wall-E é fazer perguntas como: "O ser humano é dono da natureza ou parte dela?" e, "A lei é suficiente para conscientizar as pessoas sobre a importância do meio ambiente?";

2. Assistir o Filme: Dirigido por Andrew Stanton, o filme Wall-E é uma animação que foi lançado no ano de 2008 nos Estados Unidos e têm 97 minutos de duração. A história do filme se passa no futuro, onde Wall-E, o último robô em funcionamento no planeta Terra, tem a missão de reciclar o excesso de lixo produzido pelos humanos, a fim de tornar viável a sobrevivência no planeta Terra. A ideia era que a tripulação humana, refugiada em uma estação aérea, retornasse em cinco anos, porém, o ar da Terra se tornou muito tóxico para suportar a vida, forçando a humanidade a permanecer longe. Certo dia, Wall-E descobre uma pequena planta crescendo entre o lixo e a leva para casa, um depósito. Mais tarde, uma nave aterrissa e implanta EVA, um avançado robô enviado no intuito de procurar sinais de vegetação na Terra. Wall-E se apaixona por EVA. Quando ele a leva ao depósito para mostrar a planta, ela automaticamente a guarda e envia um sinal de recolhimento para a nave, que retorna ao espaço, levando Wall-E que se segura no casco da nave e chega a estação aérea onde estão os humanos. Neste lugar, em meio a muitas aventuras, o capitão da nave decide voltar a Terra, pois considera que a planta é um sinal de que a mesma 
pode ser novamente reabitada e, após tentativa de impedimento pelo piloto automático da nave, ele retorna com a tripulação à Terra na expectativa de recolonizá-la e restaurar o meio ambiente do planeta que até então estava impossibilitado de sustentar a vida humana. O filme Wall-E é uma visão quase apocalíptica para o futuro do planeta no que tange à questão ambiental. É uma trama criativa que salienta a questão da preservação do planeta Terra. Nela, Wall-E, pequeno e de aparência frágil recicla o lixo. Embora seja o único da sua espécie ainda em atividade, não desanima com sua missão. Destaca-se, além de um mundo abandonado e destruído, uma humanidade corrompida pelo completo ócio e pela publicidade massiva. Além disso, o filme faz uma crítica severa ao sistema predatório de exploração dos recursos naturais que existem atualmente. Consequentemente, mostra em sua narrativa, o impacto causado pelo consumo desenfreado da humanidade, bem como dialoga com temas sobre reciclagem, poluição, esperança, atitude, solidariedade, amor, dentre outros;

3. Após a exibição do Filme: Após a exibição do filme é possível fazer, segundo Nazário (2005, p. 544) "coletivamente a reconstrução do conteúdo por meio de perguntas simples, procurando identificar partes relevantes para que todos tenham uma noção de conjunto, explicitando o discurso do vídeo". Assim, após assistirem ao filme Wall-E pode-se pedir para que os alunos destaquem as partes que mais gostaram do filme e voltar às questões feitas no inicio do filme: "O ser humano é dono da natureza ou parte dela?" e, "A lei é suficiente para conscientizar as pessoas sobre a importância do meio ambiente?". Através das respostas pode-se fazer uma discussão sobre os conceitos de Antropocentrismo, Holismo, Sociedade de Consumo, Moral e Lei.

\section{Conceitos a serem trabalhados (Proposta interdisciplinar)}

\section{Antropocentrismo e holismo}

Através da primeira pergunta, é possível esclarecer a definição dos conceitos de "antropocentrismo" e "holismo". O primeiro conceito pressupõe o homem como dono da natureza e assim, no direito de fazer o que quiser com a mesma, sem pensar nas futuras gerações. Pela visão holística, por sua vez, o ser humano se vê como parte da natureza e, por isso, tem por ela respeito, cuidado e austeridade. Neste sentido, Santos (2006) defende que é necessário

ter uma visão de caráter geral, que podemos chamar de holística, deixando-se de lado a visão estreita antropocêntrica. Pois, partindo-se desta última visão e preconceitos em relação à natureza e sua importância como um complexo homogêneo, o homem estaria acima dela, observando-a como um ser superior e a natureza existiria apenas para servi-lo. Já partindo-se de uma visão global, o homem passa a ser um ente integrante da natureza, como todos os outros (independentemente de se questionar sua origem), facilitando assim o entendimento das regras e princípios gerais que regem o universo. Então o ser humano estará inserido no contexto global, fazendo parte da natureza (SANTOS, 2006, p. 295). 


\section{Sociedade de Consumo}

Pode-se, através do filme Wall-E, levar os alunos a reflexão das conseqüências ambientais do consumo desenfreado. Este consumo fere a natureza de duas formas diferentes: seja pelo uso dos recursos naturais que são empregados para produzi-los, seja pela quantidade de resíduos sólidos que estes produtos geram no ambiente ao serem descartados, ou, porque não se enquadram mais como sendo "da moda", pois outra tendência diferente já está "em alta", ou, seja porque, como no caso dos eletrônicos, estragaram e não tem mais utilidade diária o que se denomina obsolescência programada ${ }^{1}$. Sobre o consumo dos recursos ambientais Milaré (2004) destaca que

[...] estamos consumindo $20 \%$ além da capacidade planetária de suporte e reposição. As contas mostram que a Terra tem 11,4 bilhões de hectares-terrestres e marinhosconsiderados produtivos e sustentáveis, isto é, com capacidade de renovação. Mas já está sendo usado o equivalente a 13,7 bilhões de hectares para produzir alimentos, água, energia. A diferença- 2,3 bilhões- sai de estoques não renováveis, configurando uma crise sem precedentes. (MILARÉ, 2004, p. 111.)

\section{Moral e Lei}

Através da questão: "A lei é suficiente para conscientizar as pessoas sobre a importância do Meio ambiente?" pode-se fazer a distinção entre moral e lei. Enquanto a primeira é o conjunto de regras de comportamentos relativos a determinado grupo humano, que varia de acordo com o tempo e com o espaço, a lei é regida pela coerção, ou seja, independe da conduta de determinado grupo e deve ser cumprida, na teoria, por todos dentro de um país, estado ou município. Quanto à suficiência das leis para a conscientização sobre a importância do meio ambiente, esclareceu-se que elas nem sempre elas são suficientes, seja porque alguns grupos humanos têm moralmente atitudes que são consideradas como corretas, mesmo que sejam legalmente erradas. Um exemplo de tal atitude são as queimadas. De acordo com a lei, hoje é crime ambiental realizá-la, porém, algumas famílias ligadas ao meio rural concebem que esta é a melhor maneira de iniciar uma plantação, pois seus pais assim faziam e, que por sua vez, seguiam as mesmas condutas que seus pais, e assim por diante, ou seja, um costume passado de geração a geração e que, portanto, é considerado moralmente correto, mesmo que se saiba que é legalmente errado.

Outro motivo que faz com que as leis não sejam suficientes para proteger ao meio ambiente é a destacada por Nalini (2001, p. XXIII), ele afirma que "a lei ambiental não tem sido freio suficiente. A proliferação normativa desativa a força intimidatória do ordenamento. Outras vezes, a sanção é irrisória e vale a pena suportá-la, pois a relação custo/benefício estimula a vulneração da norma". Ou seja, muitas vezes a multa pela desobediência as leis ambientais é inferior ao lucro que o infrator obtém ao desobedecê-la.

\footnotetext{
${ }^{1}$ Obsolescência programada é definida por Bulow (1986) como a produção de bens antieconômicos, com curto tempo de uso, assim os consumidores tendem a substituir os equipamentos por outros mais modernos.
} 
Ao integrar a temática Educação Ambiental dentro da disciplina de filosofia pode-se contribuir para a formação humana dos alunos por trabalhar com questões que envolveram o relacionamento deles com o meio ambiente e sua postura em relação ao mesmo. Sobre a formação humana Severino (2012) afirma que

\begin{abstract}
Na cultura ocidental, a educação foi sempre vista como processo de formação humana. Essa formação significa a própria humanização do homem, que sempre foi concebido como um ente que não nasce pronto, que tem necessidade de cuidar de si mesmo como que buscando um estágio de maior humanidade, uma condição de maior perfeição em seu modo de ser humano. Portanto, a formação é processo do devir humano como devir humanizador, mediante o qual o indivíduo natural devém um ser cultural, uma pessoa - é bom lembrar que o sentido dessa categoria envolve um complexo conjunto de dimensões que o verbo formar tenta expressar: constituir, compor, ordenar, fundar, criar, instruirse, colocar-se ao lado de, desenvolver-se, dar-se um ser (SEVERINO, 2012, p. 621).
\end{abstract}

Assim, este trabalho procurou demonstrar através de uma "proposta" interdisciplinar entre Ética e Cinema que abordar temáticas ambientais e contribuir para a Educação Ambiental é possível dentro da disciplina Filosofia.

\title{
CONCLUSÕES
}

A disciplina Filosofia se tornou obrigatória dentro do currículo escolar em 2008 e permanece até o presente momento. A Educação Ambiental é uma temática que deve estar no currículo escolar, porém, não como disciplina obrigatória. Para aproximar Ensino de Filosofia e Educação Ambiental o cinema é um ótimo aliado pedagógico, pois ele chama a atenção dos jovens do Ensino Médio.

Assim, através de uma "proposta" pedagógica que compreende três momentos - 1) sensibilização antes da exibição do filme através das questões "O ser humano é dono da natureza ou parte dela?" e, "A lei é suficiente para conscientizar as pessoas sobre a importância do meio ambiente?"; 2) Exibição do filme Wall-E; 3) Discussão dos conceitos de Antropocentrismo, Holismo, Sociedade de Consumo, Moral e Lei, é possível integrar Educação Ambiental e Ensino de Filosofia através da utilização do cinema.

Através da interdisciplinaridade entre Ética e Cinema, ou seja, da discussão de alguns conceitos através do filme Wall-E, os alunos passam a ter a oportunidade de perceber qur స?vem ter uma postura harmônica quanto ao meio ambiente e que necessitam preservar no $h$ para que o Planeta Terra não sofra consequências desastrosas no amanhã.

\section{REFERÊNCIAS}

BARBOSA, Claudio L. de. 0 ensino de filosofia na educação agrícola de nível médio: perspectivas e desafios. Disponível em: 
http://www.unioeste.br/cursos/cascavel/pedagogia/eventos/2008/1/Artigo\%2078.pdf. Acesso em 09 de outubro de 2011.

BULOW, Jeremy. An Economic Theory of Planned Obsolescence in, The QuarterlyJournal of Economics, Vol. 101, No. 4, p. 729 ,The MIT Press Novembro/1986.

GONÇALVES, Glaciane Neves; CRUZ-SILVA, Claudia T. A. da. Análise dos conhecimentos sobre problemas ambientais dos alunos do ensino fundamental e ensino médio da rede pública.Revista eletrônica do mestrado em educação ambiental. Rio Grande do Sul. v. 23. jul/dez. 2009.

MILARÉ, Edis. Direito do Ambiente. São Paulo: Revista dos Tribunais, 2004.

NALINI, José Renato. Ética Ambiental. Campinas: Millennium, 2001.

NAZÁRIO, Clarissa de L. Vídeo: Reflexões sobre a Linguagem e o Uso na Educação. In: PHILIPPI JR, Arlindo; PELICIONI, Maria C. F. (Orgs.). Educação Ambiental e Sustentabilidade. Barueri, SP: Manole, 2005.

SANTOS, Antônio Silveira Ribeiro dos. Direito Ambiental: Surgimento, Importância e Situação Atual. In: BITTAR, Eduardo C. B. (org.) História do Direito Brasileiro: leituras de ordem jurídica nacional. São Paulo: Atlas, 2006.

SEVERINO, Antônio Joaquim. A busca do sentido da formação humana: tarefa da Filosofia da Educação. Educação e Pesquisa, São Paulo, v.32, n.3, p. 619-634, set./dez. 2006. Disponível em: http://www.scielo.br/pdf/ep/v32n3/a13v32n3.pdf. Acesso em: 10 de abril de 2012.

\section{Referência Cinematográfica}

Wall-E. Direção de Andrew Stanton. Estados Unidos: PixarAnimationStudios, 2008. 1 DVD (97 min), son., col., Filme dublado. 